\title{
Obstetric outcome in twin gestation with reference to chorionicity
}

\author{
Lekshmi Murukesan, Mayadevi Brahmanandan²*, Sujamol Jacob²
}

\begin{abstract}
${ }^{1}$ Department of Obstetrics and Gynecology, Sree Gokulam Medical College, Thiruvananthapuram, Kerala, India ${ }^{2}$ Department of Obstetrics and Gynecology, Government Medical College, Thiruvananthapuram, Kerala, India
\end{abstract}

Received: 08 October 2017

Accepted: 11 October 2017

\section{*Correspondence:}

Dr. Mayadevi Brahmanandan,

E-mail: drbmaya @gmail.com

Copyright: $\odot$ the author(s), publisher and licensee Medip Academy. This is an open-access article distributed under the terms of the Creative Commons Attribution Non-Commercial License, which permits unrestricted non-commercial use, distribution, and reproduction in any medium, provided the original work is properly cited.

\section{ABSTRACT}

Background: Monochorionic twin pregnancies are at greater risk for growth abnormalities and other complications. This study aims to outline the obstetric problems faced by twins in general and also to determine the influence of chorionicity on pregnancy and perinatal outcome in twins. Objective of present study was to compare the obstetric and perinatal outcome between monochorionic and dichorionic twins.

Methods: A clinical non-interventional prospective observational study was conducted in a tertiary care hospital over a period of 1 year. 232cases of twin pregnancies were followed up from first trimester. The antepartum complications, mode of delivery, presentation, pregnancy outcome, condition of babies and perinatal mortality were compared between mono-chorionic and dichorionic twins.

Results: Among 232 cases of twins studied, 2/3rd were dichorionic and 1/3rd were monochorionic. The mean gestational age for Monochorionic (MC) twins was 33.2 weeks whereas it was 35.6 weeks for Dichorionic (DC) twins. Preterm delivery was significantly associated with mono-chorionicity. Elective CS was done more for MC twins compared to DC twins. The mean birth weight of MC twins was $1.7 \mathrm{~kg}$ compared to $2.1 \mathrm{~kg}$ among DC twins. Low APGAR scores were seen in $31.3 \%$ of MC twins compared to $15.8 \%$ of DC twins. The number of asphyxiated babies (12.5\%), stillborn (7.5\%) and macerated babies (10\%) were more in MC group in comparison to DC group where it was $(9.9 \%, 2.1 \%, 0.7 \%)$ respectively. Risk of IBN admissions were more in MC than DC twins. (31.3\% Vs $21.1 \%$ ) Adverse perinatal outcome was associated more with MC pregnancies (37.5\%) than DC. (11.8\%).

Conclusions: Mono-chorioncity was significantly associated with pregnancy complications and adverse perinatal outcome. Hence early diagnosis of chorionicity and referral to a tertiary centre with fetal medicine unit and newborn care is very important in reducing morbidity and perinatal mortality among MC twins.

Keywords: Dichorionic, Monochorionic, Pregnancy outcome, Perinatal outcome

\section{INTRODUCTION}

Twinning is one of the most interesting events occurring in human reproductive biology. At present, multiple pregnancy accounts for $3 \%$ of all the pregnancies (ACOG, 1998), out of which $94 \%$ are twins.

In India, twins account for $1 \%$ of all pregnancies, but contribute to $10 \%$ of perinatal mortality. ${ }^{1,2}$ Twin pregnancies are also responsible for $12.2 \%$ of preterm births and $15.4 \%$ of neonatal deaths. ${ }^{3,4}$

Over the last few decades, the incidence of twinning has been on the rise. This significant increase was not only due to the postponement of maternity, but also due to inadvertent use of ovulation induction drugs in artificial reproductive techniques. Perinatal morbidity and mortality was higher among multiple gestations due to 
increased incidence of ante-partum complications, preterm labour and utero-placental insufficiency.

Zygosity refers to the type of conception and chorionicity refers to placentation. Among twins, $30 \%$ are identical or monozygotic and $70 \%$ are fraternal or dizygotic. In comparison to dichorionic twins, $15-20 \%$ of monochorionic twins have increased risk of complications due to imbalance in placental sharing between fetuses.

Studies have shown that monochorionicity is associated with higher perinatal mortality and with increased incidence of preterm births, low birth weight and prolonged stay in neonatal ICU. ${ }^{5-7}$

Objective of present study was to compare the obstetric and perinatal outcome between monochorionic and dichorionic twins.

\section{METHODS}

This was a clinical, non-interventional descriptive study which was conducted at SATH, Medical College, Thiruvananthapuram, which is a tertiary care hospital, over a period of one year. A detailed history was taken, clinical examination and analysis of investigation including ultrasound were done. Consent was obtained from the patients included in the study. Institutional Ethics committee clearance was also obtained.

\section{Inclusion criteria}

There was a total of 15310 deliveries during the study period, of which there were 252 cases of twin pregnancies. 232 cases of twin pregnancies who had a first trimester detection of chorionicity by ultrasound, who subsequently delivered in the same hospital, were enrolled into the study.

\section{Exclusion criteria}

Those twins which suffered miscarriage in the first trimester itself, and / or whose chorionicity was not commented by the ultrasound scan was excluded from the study.

These patients were followed from antenatal period upon their registration in $\mathrm{OP}$, and after admission, through their delivery and until discharge from hospital. The antepartum complications, mode of onset of labour, mode of delivery, condition of the newborns and perinatal outcome was studied with special reference to chorionicity.

Chorionicity was diagnosed on the basis of first or second trimester ultrasound and confirmed by examination of placenta postnatally. Chorionicity was classified as dichorionic diamniotic (DCDA), monochorionic
diamniotic(MCDA) and monochorionic monoamniotic (MCMA).

Preterm delivery was defined as delivery before 37 completed weeks of gestation. Perinatal mortality was defined as death of an infant $>500 \mathrm{gms}$ within 1 week after delivery, including stillbirth.

Stillbirth was defined as intrauterine demise of a fetus $>500 \mathrm{~g}$ and $>$ or $=20$ completed weeks of gestation. Early neonatal death was defined as death of an infant during the first 7 days of life and late neonatal death as death between 8 and 28 days after birth.

\section{Statistical analysis}

Statistical methods used to analyze the results were chisquare tests and students tests. $\mathrm{P}<0.05$ was taken as significant. Data entry was done using Microsoft excel and analysis done using SPSS.

\section{RESULTS}

There was a total of 232 cases of twin deliveries during the 1 year study period. There were 152 cases of DCDA twins $(65.5 \%)$ and 80 monochorionic twins $(34.5 \%)$ of which 74 were monochorionic diamniotic and 6 were monochorionic monoamniotic twins. $2 / 3^{\text {rd }}$ were dichorionic twins whereas $1 / 3^{\text {rd }}$ were monochorionic twins.

Table 1: Pregnancy outcome with respect to chorionicity.

\begin{tabular}{|lll|}
\hline Parameter & P value & $\chi^{2}$ \\
\hline Twin complications & $<0.01$ & 43.4 \\
\hline Obstetric complications & $>0.05$ & 32.39 \\
\hline Medical disorders & $>0.05$ & 12.297 \\
\hline Presentation & Not significant \\
\hline Prematurity & $<0.01$ & \\
\hline Mode of onset of labour & $>0.05$ & 1.48 \\
\hline Mode of delivery & Comparable \\
\hline Post-partum complications & Comparable \\
\hline Time interval between delivery & Comparable \\
\hline Nursery admission & $<0.01$ & 4.157 \\
\hline APGAR & $<0.01$ & 20.978 \\
\hline Discordance at birth & $<0.01$ & 15.689 \\
\hline Perinatal mortality & $<0.01$ & 22.647 \\
\hline Birth weight & $<0.01$ & 20.82 \\
\hline
\end{tabular}

The summary of present findings is listed in Table 1.

Obstetric complications peculiar to twins were seen in 85 1232 cases $(36.6 \%)$.

TWIN complications were seen more in monochorionic twins, $55 \%$ compared to $19.8 \%$ in dichorionic twins and the finding was statistically significant (Table 2). 
Table 2: Twin complications.

\begin{tabular}{|c|c|c|c|c|}
\hline \multirow{2}{*}{ Complications } & \multicolumn{2}{|c|}{ Monochorionic } & \multicolumn{2}{|c|}{ Dichorionic } \\
\hline & No. & $\%$ & No. & $\%$ \\
\hline \multicolumn{5}{|c|}{ Fetal growth abnormalities } \\
\hline IUGR & 14 & 18.2 & 10 & 7 \\
\hline Discordance & 10 & 13 & 8 & 5.6 \\
\hline Congenital anomalies & 5 & 6.5 & 2 & 1.4 \\
\hline Abnormal doppler & 3 & 3.9 & 1 & 0.7 \\
\hline \multicolumn{5}{|l|}{ Fetal demise } \\
\hline Fetus papyraceus & 1 & 1.3 & 3 & 2.1 \\
\hline SFD & 12 & 15.6 & 5 & 3.5 \\
\hline Both IUD & 3 & 3.9 & 2 & 1.4 \\
\hline \multicolumn{5}{|l|}{ Vascular accidents } \\
\hline Conjoined twin & 1 & 1.3 & - & - \\
\hline TTTS & 4 & 5.2 & - & - \\
\hline \multirow[t]{2}{*}{ Cord entanglement } & 2 & 2.6 & - & - \\
\hline & 55 & 68.75 & 30 & 19.73 \\
\hline
\end{tabular}

\section{Presentation and frequency of presentation}

$32.4 \%$ of all the twins had a non-vertex presentation. The commonest presentation frequency amongst twins were that of vertex- vertex $(40.9 \%)$. The frequency of presentation was also comparable for both the types.

Table 3: Frequency of presentation.

\begin{tabular}{|lllllll|}
\hline Presentation & MC & $\%$ & DC & $\%$ & Total & $\%$ \\
\hline Vertex-vertex & 30 & 37.6 & 66 & 43.4 & 96 & 40.9 \\
\hline Vertex- breech & 24 & 30 & 34 & 22.4 & 58 & 25 \\
\hline Breech-breech & 15 & 18.8 & 32 & 21.1 & 47 & 20.3 \\
\hline Breech-vertex & 8 & 10 & 14 & 9.2 & 22 & 9.5 \\
\hline $\begin{array}{l}\text { Vertex- } \\
\text { transverse }\end{array}$ & 1 & 1.3 & 2 & 1.3 & 3 & 1.3 \\
\hline $\begin{array}{l}\text { Breech- } \\
\text { transverse }\end{array}$ & - & - & 4 & 2.6 & 4 & 1.7 \\
\hline $\begin{array}{l}\text { First } \\
\text { transverse }\end{array}$ & 2 & 2.5 & - & - & 2 & 0.9 \\
\hline Total & 80 & 100 & 152 & 100 & 232 & 100 \\
\hline
\end{tabular}

\section{Gestational age at termination of pregnancy}

$75.4 \%$ of all the twins suffered a preterm birth of which $28 \%$ were extreme pre-term and $44.4 \%$ were near term, which is a significant finding in present study.

Table 4: Gestational age at termination of pregnancy.

\begin{tabular}{|lllllll|}
\hline $\begin{array}{l}\text { Gestational } \\
\text { age }\end{array}$ & MC & $\%$ & DC & $\%$ & Total & $\%$ \\
\hline$<20$ weeks & 5 & 6.3 & 2 & 1.3 & 7 & 3 \\
\hline 20-28 weeks & 7 & 8.8 & 4 & 2.6 & 11 & 4.7 \\
\hline 28-34 weeks & 21 & 26.3 & 33 & 21.7 & 54 & 23.3 \\
\hline 34-37 weeks & 35 & 43.8 & 68 & 44.7 & 103 & 44.4 \\
\hline $37-40$ weeks & 12 & 15 & 45 & 29.6 & 57 & 24.6 \\
\hline Total & 80 & 100 & 152 & 100 & 232 & 100 \\
\hline
\end{tabular}

\section{Prematurity and chorionicity}

Prematurity and chorionicity is elaborated in Table 4. Prematurity was significantly associated with monochorionicity. The mean gestational age at delivery of monochorionic twins in this study was 33.2 weeks, whereas it was 35.6 weeks for dichorionic twins.

\section{Mode of onset of labour}

Mode of onset of labour was spontaneous in majority of twins, irrespective of their chorionicity. Elective caesarian section was done more for monochorionic compared to dichorionic twins $\left(\mathrm{x}^{2}=1.478 \mathrm{p}=\right.$ Not significant).

\section{Mode of delivery}

LSCS rates was high for twins compared to singletons, being done for $46.1 \%$ of all the twins. $36.3 \%$ of monochorionic twins had LSCS whereas $51.3 \%$ of dichorionic twins had LSCS. Majority of MCMA twins were delivered by elective CS (Table 5).

Table 5: Mode of delivery.

\begin{tabular}{|c|c|c|c|c|c|c|c|}
\hline \multirow{2}{*}{\multicolumn{2}{|c|}{$\begin{array}{l}\text { Mode of delivery } \\
\text { Miscarriage (14-20weeks) }\end{array}$}} & \multicolumn{2}{|c|}{ Monochorionic number (\%) } & \multicolumn{2}{|c|}{ Dichorionic number (\%) } & \multicolumn{2}{|c|}{ Total twins number } \\
\hline & & 5 & $5(6.3 \%)$ & 2 & $2(1.4)$ & 7 & $7(3.1)$ \\
\hline \multirow{4}{*}{ Vaginal } & Spontaneous & 42 & \multirow{4}{*}{$46(57.4 \%)$} & 44 & \multirow{4}{*}{$\begin{array}{l}72 \\
(47.3)\end{array}$} & 86 & \multirow{4}{*}{$118(50.8)$} \\
\hline & Induced & 2 & & 7 & & 14 & \\
\hline & Instrumental & 2 & & 18 & & 20 & \\
\hline & VBAC & - & & 3 & & 3 & \\
\hline \multirow{2}{*}{ LSCS } & Elective & 17 & \multirow{2}{*}{$29(36.3 \%)$} & 31 & \multirow{3}{*}{$\begin{array}{l}78 \\
(51.3)\end{array}$} & 48 & \multirow{2}{*}{$107(46.1)$} \\
\hline & Emergency & 12 & & 47 & & 59 & \\
\hline Total & & 80 & & 152 & & 232 & \\
\hline
\end{tabular}

\section{Perinatal outcome}

The number of asphyxiated babies (12.5\%), stillborn $(7.5 \%)$ and macerated babies $(10 \%)$ were more in MC group in comparison to dichorionic where it was $(9.9 \%$,
$2.1 \%, 0.7 \%$ ) respectively. Adverse perinatal outcome was associated more with MC pregnancies $(37.5 \%)$ than DC. $(11.8 \%)$ The risk of macerated fetuses, stillbirths and severely asphyxiated babies were significantly more associated with monochorionic twins. $\mathrm{x}^{2} 17.417, \mathrm{p}<0.05$. 
The risk was more for second of twin compared to the first. $x^{2}=21.236$ (Figure 1).

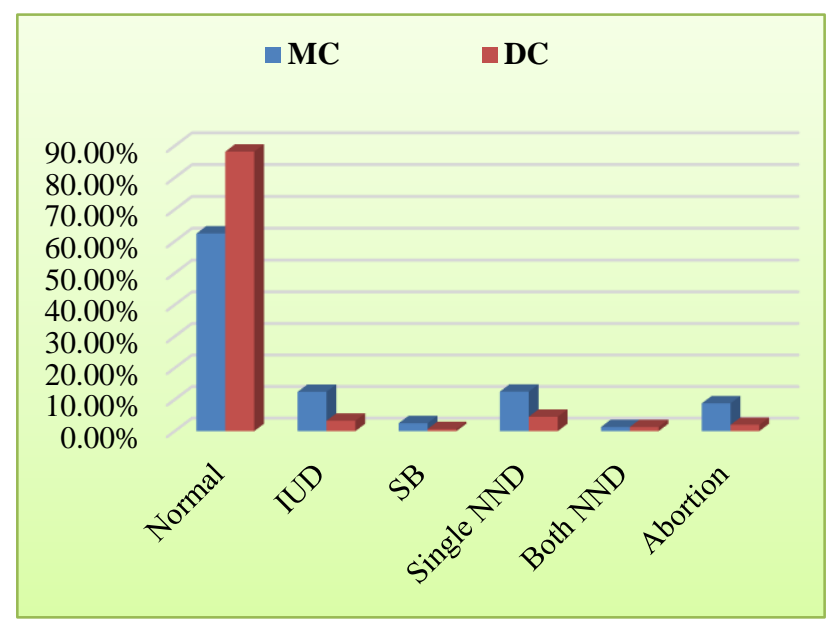

Figure 1: Perinatal outcome of twins.

\section{Sex of babies}

Monochorionic twinning was associated with like sexed babies only. Whereas $36.8 \%$ of dichorionic twins were unlike-sexed. This association was statistically significant. Incidence of both female babies was significantly more than both males (Table 6).

Table 6: Sex of babies.

\begin{tabular}{|c|c|c|c|c|c|c|}
\hline $\begin{array}{l}\text { Sex of } \\
\text { babies }\end{array}$ & MC & $\%$ & DC & $\%$ & Total & $\%$ \\
\hline Both Males & 34 & 42.5 & 44 & 28.9 & 78 & 33.6 \\
\hline Both females & 46 & 57.5 & 52 & 34.2 & 89 & 38.4 \\
\hline $\begin{array}{l}\text { Male and } \\
\text { female }\end{array}$ & - & - & 56 & 36.8 & 65 & 28 \\
\hline Total & 80 & 34.5 & 152 & 65.5 & 232 & 100 \\
\hline
\end{tabular}

\section{Birth weight of babies}

The mean birth weight of MC twins was $1.7 \mathrm{~kg}$ compared to $2.1 \mathrm{~kg}$ among DC twins. Low birth weights were significantly associated with mono-chorionic twins and with the second of twin $\left(\mathrm{X}^{2}=20.802 \mathrm{P}<0.10\right)$.

\section{Apgar score of babies}

Low APGAR scores were seen in $31.3 \%$ of MC twins compared to $15.8 \%$ of DC twins and association with monochorionicity was statistically significant. The second of twin was associated with low Apgar scores compared to the first.

\section{Neonatal ICU admission}

Risk of NICU admissions were more in MC than DC twins (31.3\% Vs 21.1\%) (Table 7).
Table 7: NICU admission.

\begin{tabular}{|lllllll|}
\hline NICU care & MC & $\%$ & DC & $\%$ & Total & $\%$ \\
\hline Needed & 25 & 31.3 & 32 & 21.1 & 57 & 24.6 \\
\hline Not needed & 55 & 68.8 & 120 & 78.9 & 175 & 75.4 \\
\hline Total & 80 & 34.5 & 152 & 65.5 & 232 & 100 \\
\hline$X^{2}=4.157 ; p<0.005$ & & & & & \\
\hline
\end{tabular}

\section{Discordance detected at birth}

Incidence of birth weight discordance was more in the monochorionic twins in comparison to dichorionic twins. Thus, the association between discordance and chorionicity was found to be statistically significant (Table 8).

Table 8: Discordancy.

\begin{tabular}{|l|llll|ll|}
\hline Discordancy & MC & $\%$ & DC & $\%$ & Total & $\%$ \\
\hline Present & 32 & 40 & 25 & 16.4 & 57 & 24.6 \\
\hline Absent & 48 & 60 & 127 & 83.6 & 175 & 75.4 \\
\hline Total & 80 & 34.5 & 152 & 65.5 & 232 & 100 \\
\hline
\end{tabular}

\section{DISCUSSION}

\section{Fetal complications}

In comparison to dichorionic twins, $15-20 \%$ of the monochorionic twins have increased risk of complications due to imbalance in placental sharing. Incidence of fetal complications like congenital malformations, discordant growth, IUGR, TTTS and antepartum fetal demise were all higher in monochorionic compared to dichorionic twins. Studies by Chauhan et al showed a prevalence of IUGR in $46 \%$ of monochorionic twins compared to $26 \%$ of dichorionic. ${ }^{8}$ Domingues et al also has found a higher incidence of growth discordance among monochorionic twins $(24.1 \%$ in MC Vs $12.1 \%$ in DC). ${ }^{9}$ Results were comparable to studies by Sebire et al. ${ }^{10}$

\section{Frequency of presentation}

Majority of the monochorionic (37.6\%) and dichorionic, $(43.4 \%)$ twins presented as vertex-vertex. Malpresentations in the second of twin was common in MC twin $(50 \%)$ compared to DC $(47.4 \%)$. Malpresentation in the 1st of twin was similar in both monochorionic and dichorionic twins $(31.3 \%$ versus $32.9 \%)$. In a study conducted by Divon and colleagues, the reported incidence of Vertex-Vertex was $42 \%$ and Vertex-Breech was $27 \% .^{11}$

\section{Gestational age at delivery}

Mean gestational age at delivery of monochorionic twin in this study was 33.2 weeks whereas it was 35.6 weeks for dichorionic twins. 
According to Smits $\mathrm{J}$, preterm labor is the one major complication on which zygosity has an influence. ${ }^{12}$ The present study also supports this. In a study conducted by Hatkar et $\mathrm{al}^{13}$ and colleagues of 100 twin pregnancies, they identified the average gestational age of monochorionic as 35.5 weeks and dichorionic as 35.7 weeks. ${ }^{13}$ In a study conducted by Radhakrishnan $\mathrm{R}$ at Calicut medical college during the same time period, the gestational age for monochorionic twins was found to be $35.7 \%$ and dichorionic was $36.5 \%$ and the incidence of preterm labour was $45 \% .^{14}$

Cheung YB et al suggested optimum gestational age of twins was between 37 and 39 weeks. ${ }^{15}$ Increased incidence of preterm babies in monochorionic twin population may due to higher incidence of preterm premature rupture of membranes, polyhydramnios etc.

\section{Mode of onset of labour}

Onset of labour was spontaneous in (62.5\%) monochorionic and (57.9\%) of dichorionic twins. Induction was more in dichorionic twins (19.7\%) compared to monochorionic (13.8\%). In studies by Radhakrishnan R, $84.5 \%$ of twins went into spontaneous onset of labour and $15.5 \%$ was induced. ${ }^{14}$

\section{Mode of delivery}

Elective caesarian section was done more for monochorionic $(22.5 \%)$ compared to dichorionic (21.7\%) twins. This can be attributed to risk of twin complications like discordance, IUGR, TTTS.

The rate of caesarian section in previous studies done in the hospital were $19.7 \%$ in 1986 and $27.37 \%$ in 1994. Among the MCMA twins, 2 of them delivered vaginally spontaneously. Majority of MCMA twins were delivered by Elective caesarian section (50\%). Among MCDA twins, $58.8 \%$ of them delivered vaginally spontaneously. Emergency caesarian was done for another $8.8 \%$ for other reasons. Elective caesarian was done for $16.2 \%$. Majority of the DCDA delivered spontaneously.

Emergency caesarian section was done for $25.4 \%$ and elective caesarian for $20.4 \%$. There were 3 cases of vaginal birth after caesarian section. In studies by Radhakrishnan R, $62.5 \%$ of twins delivered vaginally and $35.5 \%$ were delivered by caesarian section of which $8 \%$ was elective CS and $27.5 \%$ was emergency CS. ${ }^{16}$ These results were comparable to studies by Samra JS et al. ${ }^{17}$

\section{Condition of babies}

The number of asphyxiated babies (12.5\%), still births $(7.5 \%)$ and macerated babies $(10 \%)$ was more in the monochorionic group compared to dichorionic, where it was $(9.9 \%$. $2.1 \%$ and $0.7 \%$ respectively). The poor perinatal outcome in monochorionic twins may be related to increased incidence antenatal complications like
IUGR, discordance TTTS etc. Incidence of congenital anomalies were comparable in both types of twins.

\section{Sex of the babies}

All the monochorionic twins were like sexed whereas $36.8 \%$ of dichorionic twins were unlike sexed. Among the like-sexed twins, incidence of both females was higher compared to males ( $P$ value $<0.001$ ). and the relation is statistically significant.

\section{Time interval between the delivery}

Time interval between delivery of the babies was not found to be significantly affected by chorionicity. Majority of the twins $58.8 \%$ of monochorionic and $67.1 \%$ of dichorionic delivered within 5 minutes.

\section{Birth weight of babies}

Risk of low birth weight babies was more for monochorionic twins compared to dichorionic. Low birth weight was associated with 2 nd of twin compared to first. Both the associations were statistically significant. In the present study, mean birth weight of monochorionic twins was $1.7 \mathrm{Kg}$ and mean birth weight of dichorionic twins was $2.1 \mathrm{Kg}$. Low birth weight was more common in monochorionic compared to dichorionic $(60 \%$ Vs 40.2\%). According to Matcher Gut et al, the mean birth weight of twins is affected by the length of pregnancy, sex of the twins and zygosity. ${ }^{18}$ Previous studies by De Assunacao et al showed mean birth weight of $2.16 \mathrm{~kg}$ for dichorionic and $1.8 \mathrm{~kg}$ for monochorionic pregnancies. ${ }^{19}$ Results were similar in studies by Blecker and Hemrika. ${ }^{20}$

\section{Apgar of babies}

Low Apgar Scores were seen in the $31.3 \%$ monochorionic twins compared to $15.8 \%$ of dichorionic twins. Apgar score was lower for the second of twin compared to first in both monochorionic and dichorionic twins. Both the associations were found to be statistically significant. It has been felt that the risk of diminished placental perfusion increases with prolonged birth interval. These were statistically significant difference at birth favoring the first twin.

\section{NICU (neonatal ICU) admission}

Risk of NICU admission was more in monochorionic gestation $31.3 \%$ compared in $21.1 \%$ of dichorionic and the association was found to be statistically significant. In studies by Hatkar et al, $6.8 \%$ of monochorionic had longer NICU stay compared to $1.75 \%$ of dichorionic twins. $^{13}$

\section{Perinatal outcome}

Adverse perinatal outcome was associated with monochorionic pregnancy $(37.5 \%)$ compared to 
dichorionic pregnancy $(11.8 \%)$ and the association was found to be statistically significant. Incidence of intrauterine death was $12.5 \%$ in monochorionic compared to $3.3 \%$ in dichorionic. Incidence of still birth and neonatal death was also higher in monochorionic compared to dichorionic This can be explained by the decreased ability of the preterm and compromised babies to withstand the stress of labour and delivery.

According to Naeye et al, the overall mortality for monozygotic twins was about 2.5 times greater than for dizygotic twins and was mainly due to amniotic fluid infection, TTTS and congenital anomalies. ${ }^{21}$

The perinatal mortality among monochorionic pregnancies was $18 \%$ and in dichorionic was $6 \%$ in studies by Radhakrishnan R. ${ }^{14}$ Another study on perinatal outcome of twins in relation to chorionicity, conducted at Nowrosjee Wadia Maternity hospital in Mumbai by Hatkar PA et al calculated a PNM of monochorionic twins to be $176.47 / 1000$ and dichorionic as $88.88 / 1000 .{ }^{13}$

\section{Discordance in birth weights}

Discordance in birth weights was seen in $40 \%$ of monochorionic compared to $16.4 \%$ of dichorionic This means that monochorionicity is associated with significant risk of discordance and the risk is found to be statistically significant. Radhakrishnan $\mathrm{R}$ in their study demonstrated discordance of $25 \%$ in dichorionic and $28 \%$ in monochorionic twins. ${ }^{14}$ Also, Sebire et al in his studies reported discordance complicates monochorionic in $11.3 \%$ and dichorionic in $12.1 \% .^{10}$

\section{Pregnancy outcome based on gestational age at delivery and chorionicity}

In the $<28$ weeks gestational age, the majority of the twins delivered were monochorionic compared to dichorionic. There were 7 cases of spontaneous abortions in the <20 weeks gestational age and 3 cases in 20-28 weeks gestage. Majority of the single fetal demise occurred between 28-34 weeks gestation. The neonatal deaths were distributed almost uniformly between 20-34 weeks gestation.

The risk of prematurity and preterm delivery was found to be significantly associated with monochorionic gestation.

\section{CONCLUSION}

Mono-chorioncity was significantly associated with pregnancy complications and adverse perinatal outcome. Hence early diagnosis of chorionicity and referral to a tertiary centre with fetal medicine unit and newborn care is very important in reducing morbidity and perinatal mortality among MC twins.

Funding: No funding sources
Conflict of interest: None declared

Ethical approval: The study was approved by the Institutional Ethics Committee

\section{REFERENCES}

1. Blondel B, Kaminski M. Trends in the occurrence, determinants, and consequences of multiple births. InSeminars in perinatology. WB Saunders. 2002 Aug;26(4):239-249.

2. Norwitz ER, Edusa V, Park JS. Maternal physiology and complications of multiple pregnancy. InSeminars in perinatology. WB Saunders. 2005 Oct;29(5):338348.

3. Ghai V, Vidyasagar D. Morbidity and mortality factors in twins. An epidemiologic approach. Clin Perinatol. 1988 Mar;15(1):123-40.

4. Gardner MO, Goldenberg RL, Cliver SP, Tucker JM, Nelson KG, Copper RL. The origin and outcome of preterm twin pregnancies. Obstet Gynecol. 1995 Apr 1;85(4):553-7.

5. Chitrit Y, Filidori M, Pons JC, Duyme M, Papiernik E. Perinatal mortality in twin pregnancies: a 3-year analysis in Seine Saint-Denis (France). European $\mathbf{J}$ Obstet Gynecol Reprod Biol. 1999 Sep;86(1):23-8.

6. Snijder MJ, Wladimiroff JW. Fetal biometry and outcome in monochorionic vs. dichorionic twin pregnancies; a retrospective cross-sectional matchedcontrol study. Ultrasound Med Biol. 1998 Feb;24(2):197-201.

7. Victoria A, Mora G, Arias F. Perinatal outcome, placental pathology, and severity of discordance in monochorionic and dichorionic twins. Obstet Gynecol. 2001 Feb;97(2):310-5.

8. Chauhan SP, Shields D, Parker D, Sanderson M, Scardo JA, Magann EF. Detecting fetal growth restriction or discordant growth in twin gestations stratified by placental chorionicity. J Reprod Med. 2004 Apr;49(4):279-84.

9. Domingues AP, Gonçalves S, Vasco E, Fonseca E, Moura P. Chorionicity in twin pregnancies: impact upon perinatal results. Acta Obstet Ginecol Port. 2007;1(4):163-6.

10. Sebire NJ, Snijders RJ, Hughes K, Sepulveda W, Nicolaides KH. The hidden mortality of monochorionic twin pregnancies. BJOG: An Int J Obstet Gynecol. 1997 Oct;104(10):1203-7.

11. Divon MY, Marin MJ, Pollack RN, Katz NT, Henderson C, Aboulafia Y et al. Twin gestation: fetal presentation as a function of gestational age. Am $\mathbf{J}$ Obstet Gynecol. 1993 May;168(5):1500-2.

12. Smits J, Monden C. Twinning across the developing world. PLoS One. 2011 Sep;6(9):e25239.

13. Hatkar PA, Bhide AG. Perinatal outcome of twins in relation to chorionicity. J Postgraduate Med. 1999 Apr;45(2):33.

14. Radhakrishnan R, Radhakrishnan R. Perinatal outcome of twin pregnancy and influence of chorionicity on it. Int J Prevent Therap Med. 2014 Mar;1(2). 
15. Cheung YB, Yip P, Karlberg J. Mortality of twins and singletons by gestational age: a varyingcoefficient approach. Am J Epidemiol. 2000 Dec;152(12):1107-16.

16. Radhakrishnan R, Radhakrishnan R. The perinatal outcome of first and second twin. Int $\mathrm{J}$ Prevent Therapeu Med. 2014 Jun 11;2(2).

17. Samra JS, Spillane H, Mukoyoko J, Tang L, Obhrai MS. Caesarean section for the birth of the second twin. BJOG: Int J Obstet Gynecol. 1990 Mar;97(3):234-6.

18. Guttmacher AF, Kohl SG. The fetus of multiple gestations. Obstet Gynecol. 1958 Nov;12(5):528-40.

19. Assunção RA, Liao AW, Brizot MD, Krebs VL, Zugaib M. Perinatal outcome of twin pregnancies delivered in a teaching hospital. Revista da Associação Médica Brasileira. 2010;56(4):447-51.

20. Bleker OP, Hemrika DJ. Gestational age according to fetal sex in twins. Am J Obstet Gynecol. 1985 Mar 15;151(6):830-1.

21. Naeye RL, Tafari N, Judge D, Marboe CC. Twins: causes of perinatal death in 12 United States cities and one African city. Am J Obstet Gynecol. 1978 Jun 1;131(3):267-72.

Cite this article as: Murukesan L, Brahmanandan M, Jacob S. Obstetric outcome in twin gestation with reference to chorionicity. Int J Reprod Contracept Obstet Gynecol 2017;6:xxx-xx. 